\title{
ANÁlise Temporal do CREscimento Vegetativo de Egeria najas A Partir de Fragmentos da Planta ${ }^{1}$
}

\author{
Temporal Analysis of Egeria najas Vegetative Growth From Plant Fragments
}

\begin{abstract}
CARVAlHO, F.T. ${ }^{2}$, VELINE, E.D. ${ }^{3}$, FRAZZATTO, E.F. ${ }^{4}$, ANJOS, F.M. ${ }^{4}$ e PERUCHI, M. ${ }^{4}$
RESUMO - O estudo de caracteres botânicos de plantas infestantes pode ser de grande valia na tomada de decisões quanto aos métodos de controle a serem empregados. O objetivo deste trabalho foi verificar o crescimento vegetativo de plantas de Egeria najas a partir de fragmentos de $5 \mathrm{~cm}$ da planta. O experimento foi desenvolvido na fazenda Nova Estrela, situada a 20³0'19,7' de latitude e 51¹4'56,3” de longitude, no município de Pereira Barreto, na região noroeste do Estado de São Paulo. O delineamento experimental utilizado foi o de blocos ao acaso, com quatro tratamentos e cinco repetições. Os tratamentos foram constituídos pelas diferentes posições dos fragmentos das plantas. No tratamento 1, os fragmentos foram retirados da extremidade final (ápice) das plantas $(0$ a $5 \mathrm{~cm}$ ); no tratamento 2, eles foram retirados com 5 a $10 \mathrm{~cm}$; no tratamento 3, dos 10 aos $15 \mathrm{~cm}$; e no tratamento 4, dos 15 aos $20 \mathrm{~cm}$. Os fragmentos foram amarrados com linhas de náilon, fixadas em um suporte de ferro, e devolvidos à água, onde permaneceram até o final do estudo. A avaliação de crescimento foi realizada aos 12 dias após os tratamentos. Observou-se que, independentemente da posição, todos os fragmentos tiveram pelo menos uma brotação, o que confirma a elevada atividade vegetativa de $E$. najas. Os fragmentos retirados do ápice foram significativamente mais ativos na retomada do crescimento, proporcionando maior número de brotos e maior comprimento.
\end{abstract}

Palavras-chave: planta aquática, planta daninha, morfologia, reprodução.

ABSTRACT - The study of the botanical characters of weeds can be valuable in the decisionmaking process for the control methods to be used. The objective of this work was to verify the vegetative growth of Egeria najas plants from $5 \mathrm{~cm}$ plant fragments. The experiment was developed at Nova Estrela Farm, located at 20'30'19.7” latitude and 51'14'56.3" longitude, in Pereira Barreto, in Northwestern São Paulo. The experiment was arranged in randomized blocks, with four treatments and five replications. The treatments consisted of different positions of the plant fragments. In treatment 1, the plant fragments were removed from the apex (0 to $5 \mathrm{~cm})$; in treatment 2, from fragments removed 5 to $10 \mathrm{~cm}$; in treatment 3, from 10 to $15 \mathrm{~cm}$ and in treatment 4, from 15 to $20 \mathrm{~cm}$. The fragments were tied with thin nylon cords, fixed in an iron support, and returned to the pond, and kept there until the end of the experiment. Growth evaluation was accomplished at 12 days after the treatments. Regardless of their position, all the fragments had at least one sprouting, confirming the high vegetative activity of E. najas. The fragments removed from the apex were significantly more active in retaking growth, providing a larger number of sprouts and greater length.

Key words: aquatic plant, weed, morphology, reproduction.

\section{INTRODUÇÃO}

As plantas aquáticas, favorecidas pelo material orgânico lançado nos rios, desenvolvem-se de forma desordenada, ocupando grandes extensões de lagos e rios. A ocorrência excessiva dessa vegetação em ambientes utilizados pelo homem causa uma série de dificuldades relacionadas à navegação, produção de energia elétrica, recreação, utilização

Recebido para publicação em 10.3.2003 e na forma revisada em 2.6.2003

2 Prof. Dr., FEIS-UNESP, Departamento de Biologia e Zootecnia; ${ }^{3}$ Prof. Dr., FCA-UNESP, Departamento de Agricultura; ${ }^{4}$ Graduandos da FEIS-UNESP. 
da água para consumo humano e animal, além de outros problemas, como a retenção de lixos e a proliferação de insetos vetores de doenças.

Existem várias espécies vegetais aquáticas que têm sido relacionadas freqüentemente nos levantamentos de plantas (Branco, 1986). Uma classificação muito utilizada e que facilita a apresentação destas plantas é quanto ao hábito de crescimento. Segundo Tanaka et al. (2002a), a classificação mais utilizada é a que divide as macrófitas em quatro grupos: emersas, emersas com folhas flutuantes, submersas e flutuantes.

Dentre as macrófitas, merecem destaque especial as plantas submersas, devido à capacidade de ocupar todo o perfil d'água em determinadas profundidades. No rio Paraná, por exemplo, mais especificamente no reservatório de Jupiá, espécies do gênero Egeria e a espécie Ceratophyllum demersum estão entre as que provocam os maiores problemas na usina hidrelétrica (Tanaka et al., 2002b).

Segundo Cook \& Urmi-König (1984), o gênero Egeria é composto por duas espécies perenes, nativas da América do Sul, disseminadas principalmente por reprodução vegetativa: Egeria densa Planch. e Egeria najas Planch.

A espécie $E$. densa tem sua descrição muito bem detalhada nas bibliografias relacionadas (Lorenzi, 2000; Kissmann, 1997), porém E. najas não apresenta ainda uma descrição pormenorizada. Mori et al. (1999), em relação a este assunto, ressaltam a importância de uma boa caracterização das populações de plantas no sentido de estabelecer controles apropriados para minimizar custos e garantir a repetitividade dos resultados de campo.

Dessa forma, o presente trabalho foi realizado com o objetivo de se fazer uma análise temporal do crescimento vegetativo de plantas de Egeria najas a partir de fragmentos do caule.

\section{MATERIAL E MÉTODOS}

O trabalho foi desenvolvido durante o mês de agosto de 2002, propositalmente antes do início do período chuvoso, de modo a evitar que as chuvas atrapalhassem a condução do ensaio. O local utilizado foi uma lagoa, infestada com Egeria najas, na fazenda Nova Estrela, situada a 20³0'19,7” de latitude sul, $51^{\circ} 14 ' 56,3$ " de longitude oeste e 377 metros de altitude, localizada no município de Pereira Barreto-SP, na região noroeste do Estado de São Paulo.

O delineamento experimental utilizado foi o de blocos ao acaso, com quatro tratamentos e cinco repetições. Os tratamentos foram constituídos pelas diferentes posições do caule, de onde foram retirados fragmentos de $5 \mathrm{~cm}$, sem brotos, das plantas de E. najas. No tratamento 1 , os fragmentos foram retirados da extremidade final (ápice) das plantas (0 a $5 \mathrm{~cm}$ ); no tratamento 2, ele foram retirados com 5 a $10 \mathrm{~cm}$; no tratamento 3 , dos 10 aos $15 \mathrm{~cm}$; e no tratamento 4 , dos 15 aos $20 \mathrm{~cm}$.

Os fragmentos foram amarrados com linhas de náilon, fixadas em um suporte de ferro, e devolvidos à lagoa, onde permaneceram até o final do experimento. Os cinco suportes de ferro, representando as repetições, foram montados e separados por distâncias de $5 \mathrm{a} 1 \mathrm{~m}$ de profundidade, com uma haste de $2 \mathrm{~m}$ apoiada em duas estacas. Em cada um destes suportes foram distribuídos os quatro tratamentos.

A avaliação de crescimento foi realizada aos 12 dias após os tratamentos (DAT). Foram analisados o número de brotos por fragmento e o comprimento total da planta de brotos.

\section{RESULTADOS E DISCUSSÃO}

A espécie Egeria najas é uma planta dióica da família das Hydrocharitaceae (Cook \& UrmiKönig, 1984). Por ter o sexo em plantas separadas, apresenta baixa capacidade de reprodução sexuada, que, no entanto, foi constatada no trabalho de Mori et al. (1999). Sem dúvida, a principal via de reprodução é a vegetativa, relatada por diversos autores (Cook \& UrmiKönig, 1984; Kissmann, 1997; Mori et al., 1999).

Os resultados observados no presente trabalho constataram a elevada atividade vegetativa das plantas de E. najas (Tabela 1).

A Tabela 1 apresenta a taxa de crescimento das plantas a partir dos fragmentos estudados. Observa-se que em todos os tratamentos ocorreu pelo menos uma brotação por fragmento e todas as plantas tiveram o comprimento final maior do que os $5 \mathrm{~cm}$ originais. 
Os fragmentos do ápice foram significativamente mais ativos na retomada do crescimento. Observa-se que o número de brotos proporcionados por fragmentos do ápice foi superior ao dos demais tratamentos, além do comprimento final (Figura 1).

Os fragmentos considerados medianos tiveram comportamento similar no número de brotos, mas observa-se nitidamente que, quanto mais próximo do ápice, mais rápida foi a retomada do crescimento da planta.

Vale ressaltar que esse tipo de informação, obtida no presente trabalho, apresenta-se como subsídio para o cultivo da planta de E. najas e, mais importante, atua como alerta para as atitudes a serem tomadas no descarte de plantas nas atividades de controle mecânico.

Tabela 1 - Crescimento de plantas de E. najas a partir de fragmentos de $5 \mathrm{~cm}$, aos 12 DAT. Pereira Barreto-SP, 2002

\begin{tabular}{|l|c|c|}
\hline \multicolumn{1}{|c|}{ Tratamento } & Número de Brotos & $\begin{array}{c}\text { Comprimento Final (cm) } \\
\text { (planta + brotos) }\end{array}$ \\
\hline 1- fragmento do ápice $(0-5 \mathrm{~cm})$ & $2,2 \mathrm{a}$ & $10,30 \mathrm{a}$ \\
\hline 2- fragmento mediano $(5-10 \mathrm{~cm})$ & $1,2 \mathrm{~b}$ & $7,20 \mathrm{~b}$ \\
\hline 3- fragmento mediano $(10-15 \mathrm{~cm})$ & $1,2 \mathrm{~b}$ & $7,10 \mathrm{~b}$ \\
\hline 4- fragmento mediano $(15-20 \mathrm{~cm})$ & $1,2 \mathrm{~b}$ & $5,98 \mathrm{~b}$ \\
\hline Média geral & 1,45 & 7,64 \\
\hline F tratamentos & $6,00 * *$ & $9,79 * *$ \\
\hline CV $(\%)$ & 31,48 & 17,34 \\
\hline DMS $(5 \%)$ & 0,857 & 2,489 \\
\hline
\end{tabular}

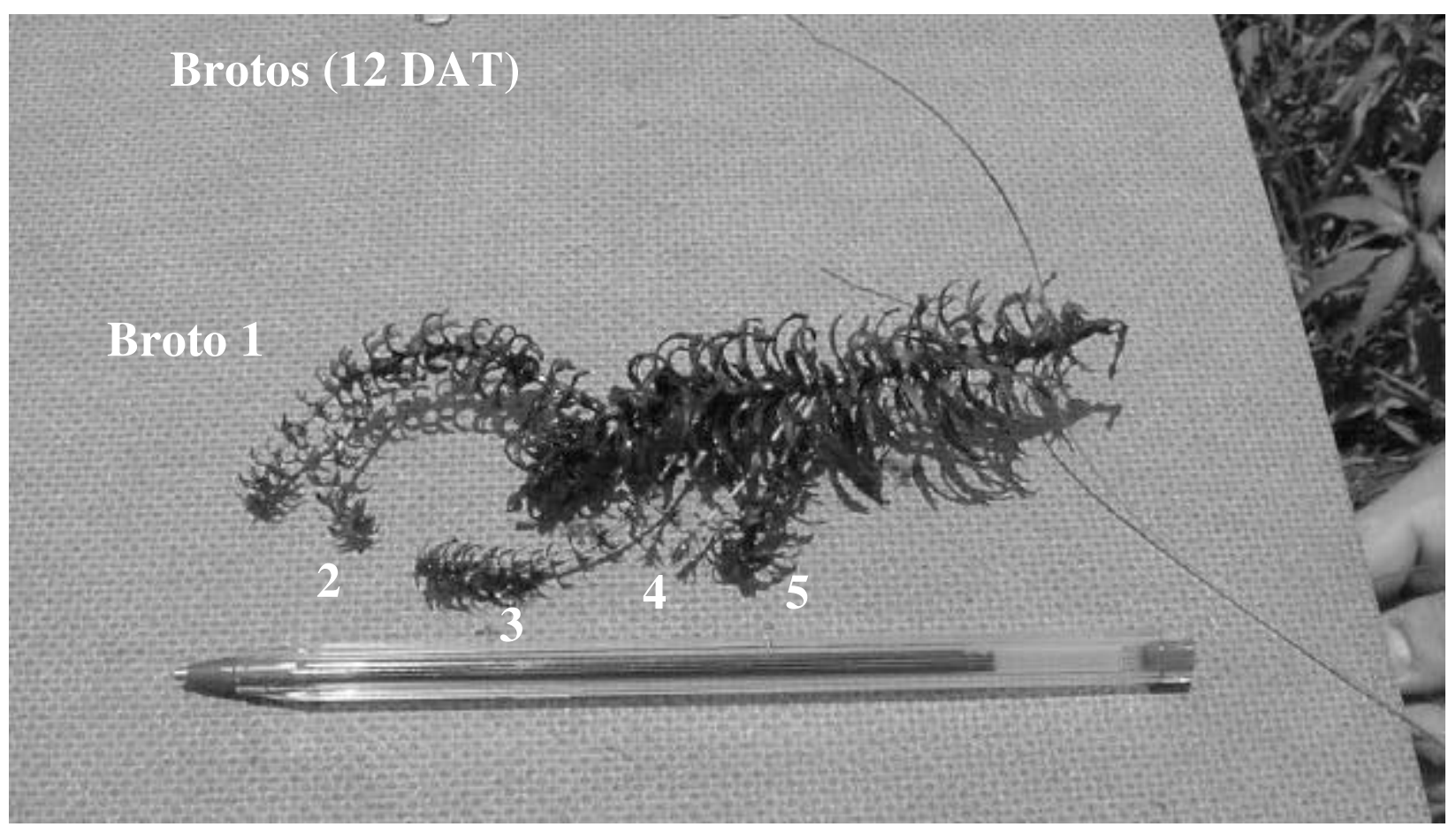

Figura 1 - Elevada atividade vegetativa do broto do ápice, aos 12 DAT. 


\section{LITERATURA CITADA}

BRANCO, S. M. Hidrobiologia aplicada à engenharia sanitária. 3.ed. São Paulo: CETESB, 1986. 616 p.

COOK, C. D. K.; URMI-KÖNIG, K. A revision of the genus Egeria (Hydrocharitaceae). Aquatic Bot., v. 19, n. 1/ 2, p. 73-96, 1984.

KISSMANN, K. G. Plantas infestantes e nocivas. 2.ed. São Paulo: BASF, 1997. 824 p. T. 1.

LORENZI, H. Plantas daninhas do Brasil: terrestres, aquáticas parasitas e tóxicas. 3.ed. Nova Odessa: Plantarum, 2000. 608 p.
MORI, E. S. et al. Caracterização genética de populações de Egeria najas no Reservatório de Jupiá e rios afluentes. Planta Daninha, v. 17, n. 2, p. 217-226, 1999.

TANAKA, R.H. et al. Ocorrência de plantas aquáticas nos reservatórios da Companhia Energética de São Paulo. Planta Daninha, v. 20, p. 99-111, 2002(a). Edição Especial.

TANAKA, R. H. et al. Avaliação de herbicidas para o controle de Egeria em laboratório, caixa d'água e represa sem fluxo de água. Planta Daninha, v. 20, p. 73-82, 2002(b). Edição Especial. 